\title{
O PAPEL SOCIAL DA OFENSA VERBAL NO JAPÃO
}

Koji Yamamoto

\section{O Samurai e a Ofensa Verbal}

O artigo 12 do código de leis Goseibai Shikimoku², promulgado pelo xogunato Kamakura (1192-1336), o primeiro governo guerreiro instalado na época Chûsei (11921540), refere-se à proibição de ofensas verbais que pode ser sintetizada em dois pontos principais:

1. a ofensa verbal é causa de brigas e assassinatos, de modo que aquele que proferi-la será penalizado;

2. aquele que proferir ofensas verbais durante o julgamento terá a causa perdida.

O primeiro registro concreto de crime de ofensa verbal data de maio de 1213: trata-se do incidente ocorrido na batalha de $\mathrm{Wada}^{3}$, em que Hatano Tadatsuna e Miura Yoshimura $^{4}$, no momento de se avaliar os feitos guerreiros, disputam entre si a primazia de avanço às hostes inimigas. Diante do xogum, Tadatsuna chama Yoshimura de "cego"

1. Professor Visitante da Universidade de Cultura e Artes de Shizuoka, Japão, junto ao curso de Pósgraduação de Língua, Literatura e Cultura Japonesa da FFLCH-USP. O presente texto é baseado na palestra proferida no Prédio de Letras da FFLCH-USP em 2001. As notas aqui apresentadas, assim como os dados referentes aos autores citados no texto, são todas de tradução.

2. Literalmente "código de medidas de punição", foi elaborado em 1232 , segundo os costumes e a jurisprudência e serviu de modelo para leis posteriores.

3. Ocorrida em 1213 e gerada pela oposição a Hojo Yoshitoki por Wada Yoshimori que sai derrotado.

4. Aliados do clã Hojo. 
ao sustentar que não o vira avançar à sua frente, sendo por isso condenado. O depoimento de testemunhas dava razão à sustentação de Tadatsuna, mas no julgamento pesou a ofensa verbal mais do que a confirmação da verdade dos fatos.

Depois desse incidente, registram-se mais de quarenta casos concretos de ofensa verbal em autos da época Kamakura. São poucos os casos de insultos de ordem geral. A maioria é de casos de ofensas contra posições e/ou classes sociais, ou ofensas que ferem a honra de outrem. Citando alguns exemplos, temos expressões como: "samurai que perdeu seu status, kanzoku no mi (desqualificado), kotoneri warawa (serviçal menino), hôtô kojiki (mendigo libertino), hôshi (monge), shirabyôshi (dançarina/prostituta), honjo onko (protegido local), bunmin (desclassificado social), rôjû̀ (vassalo menor), higokenin (vassalo de segunda categoria), genin (samurai sem amo), kanjinbôshi (monge que colhe contribuições), kôotsunin (um sujeito qualquer), onko jitô (senhor de terra sob proteção), wakatô (jovem "cheirando à fralda") que desdenham posições sociais. Mesmo quando tais expressões não eram usadas, dizer que alguém "foi expulso por ter irritado o amo" ou que "é um ex-detento" era considerado ferir a honra de outrem.

Freqüentes também eram os casos em que as palavras continham algum sentido que feria a honra do outro, apesar de elas em si não configurarem propriamente uma ofensa. Assim, por exemplo, mesmo no caso de Hatano Tadatsuna, apesar de "cego" ser em si um pejorativo, pode-se dizer que adquire um sentido mais forte quando atribuído a Yoshimura que sustenta não tê-lo visto avançar à sua frente.

As ofensas verbais que aparecem nessas ações judiciais da época Kamakura referem-se apenas a posições ou classes sociais, ou a difamações. Isso se deve à característica da sociedade guerreira da época, que valorizava sobretudo a honra.

Em outras palavras, esta era uma sociedade eminentemente guerreira, cuja função principal era lutar e na qual, universalmente falando, impera um sentimento de honra muito forte. Mesmo neste caso, Hatano Tadatsuna poderia ter aceitado a vultosa premiação proposta por Hojo Yoshitoki $i^{5}$ se cedesse a disputa para Yoshimura, uma vez que já tinha conquistado a primazia de avanço às hostes inimigas em outras investidas, mas ele recusou dizendo que não poderia comprometer o nome da família aceitando um prêmio momentâneo, e, tendo insistido numa decisão justa, acabou se excedendo nas palavras e condenado por isso.

O que mais exaltava o ânimo dos samurais eram palavras que desprezassem injustamente sua posição ou classe social, que os ferissem com fatos relacionados à sua honra, de modo que calúnias e difamações deviam ser freqüentemente objeto de disputas judiciais.

O samurai pertence a uma classe que se relaciona diretamente com a força física e, por isso, quando era vítima de algum vexame, grande era a possibilidade de apelar para soluções que implicassem a força.

A título de comparação com o Goseibai Shikimoku, gostaria de fazer uma referência à Lei Salica do povo germânico do século V a VI que, segundo consta, melhor revela o perfil da legislação germânica antiga. Há um capítulo intitulado "Sobre a ofensa verbal" que prescreve em sete artigos os crimes de maledicências, tais como:

5. Ocupou o alto posto de regente do xogum no governo Kamakura, entre 1205-1224. 
chamar uma mulher livre de prostituta; chamar alguém de raposa (no sentido de "ladino"); chamar alguém de lebre ("covarde"); dizer que o outro abandonou as armas durante a batalha; xingar o outro de mentiroso ou delator. Os germanos são conhecidos como um povo que preza a bravura e a honra e, como mostram essas normas, a ofensa verbal, também para eles, era, sobretudo, uma questão de honra.

Os dois itens do Shikimoku mencionados no início podem ser considerados, do ponto de vista tanto de sua funcionalidade quanto da aplicação da lei, como artigos distintos.

Assim, a proibição de ofensas verbais referida no item 1 pode ser considerada complementar à prescrição de penas para homicídios ou ferimentos, regulamentada no artigo 10 do mesmo código e, nesse sentido, constitui uma parte da proibição de brigas e contendas de um modo geral. Por outro lado, o item 2 constitui uma norma mais restrita na medida em que se limita a ofensas verbais proferidas no tribunal.

Com relação ao item 1, a própria ofensa verbal torna-se o tema central do julgamento, mas com relação ao item 2 , ela se torna um tema secundário do processo judicial que tem por objeto uma outra causa.

Nos registros documentais coletados, exemplos do primeiro caso são raros. Assim como o incidente de Hatano Tadatsuna, o primeiro registro de ofensa verbal, diz respeito à injúria diante do xogum, os demais casos referem-se a pronunciamentos em tribunais ou a citações em processos judiciais. Portanto, o efeito da proibição de ofensas verbais no Goseibai Shikimoku manifesta-se mais no sentido de coibir ofensas nos tribunais mais do que em simplesmente proibir ofensas e brigas em geral.

Por que, então, a ênfase dada à relação da proibição de ofensas verbais com um espaço particular que é o tribunal?

\section{2. "Festival de Insultos" e Sanção Social}

Para compreender o significado da proibição da ofensa verbal na legislação do xogunato, é necessário acrescentar algumas considerações gerais sobre a função social da ofensa verbal na sociedade japonesa em sua fase pré-moderna ${ }^{6}$

$\mathrm{Na}$ bibliografia sobre os estudos concernentes ao folclore, o conceito dos festivais denominados de akkô matsuri, akutai matsuri, ou ainda akutare matsuri, todos eventos voltados para a ofensa verbal, pode ser resumido em "festival caracterizado pela troca de maledicências entre os participantes ou pela grosseria destinada àqueles que dançam" ou, ainda, em "festival fundamentado na crença de que o vencedor da troca de ofensas verbais adquire a felicidade"

A despeito das diferenças significativas do conteúdo das cerimônias, na época do evento e em outros elementos, os festivais apresentam a troca de ofensas verbais como parte constituinte da festividade. Atualmente, a maioria desses festivais deixou de existir, e existem registros de cerca de dezessete festivais do gênero, nas diversas regiões do Japão.

6. De um modo geral, considera-se que a "modernidade" japonesa tem início com a abertura do Japão ao ocidente, em meados do século XIX, sendo a fase anterior conhecida como "pré-moderna". 
A realização dos festivais concentra-se entre o final do ano e a primeira quinzena de janeiro. Em todos eles, a ofensa verbal não constitui, por si só, seu objetivo principal e sim um papel complementar das festividades. Neste aspecto, é semelhante aos festivais conhecidos como akutai ichi ("feira" de insultos) e akutai matsuri ("festival de insultos").

O folclorista Nakayama Taro (1876-1947), provavelmente o primeiro estudioso a abordar o akkô matsuri (festival de ofensas), resume o seu conteúdo da seguinte maneira:

a) excepcionalmente na noite do festival é permitido fazer declarações sobre o comportamento alheio na vida cotidiana, algo impossível no dia-a-dia. Esse ato é concebido como uma espécie de sanção social realizada em nome de deus;

b) entretanto, o festival perdeu a forma original que era de se tirar a sorte do ano, baseando-se na crença de que o "vencedor" nessa troca de ofensas verbais seria contemplado com a sorte ao longo do ano. Segundo essa crença, a vitória é uma prova do consentimento divino ao pedido do vitorioso. Em outras palavras, "o vencedor" adquiriria a qualificação para receber a graça divina ao longo do ano.

Assim, Nakayama aponta para dois aspectos da vitória no festival de insultos: o de sanção social e o caráter de "tirar a sorte" do ano para controlar a conduta do dia-adia. Os estudos posteriores sobre o folclore tendem a enfatizar o segundo em detrimento do primeiro, dando pouca importância ao aspecto punitivo.

Outro conhecido folclorista Yanagita Kunio (1875-1962) pensava mais em termos de sanção social. Em sua obra Sairei to seken (Cerimoniais e Sociedade) ele apresenta a violência praticada pelo andor no Festival Hote do Santuário Shiogama e defende a tese de que no Japão não havia imoralidade maior do que a insensatez de se opor aos costumes da comunidade, sendo a não-punição dos infratores uma ameaça à coletividade; assim, o líder dos jovens que carregam o andor teria assumido o papel de porta-voz desse princípio social. Yanagita interpretou igualmente o festival de insultos a partir desta perspectiva analítica e, nesse sentido, pode-se afirmar que concordava com os principais pontos da tese de sanção social defendida por Nakayama.

Considerando as teses de Nakayama e Yanagita, far-se-á agora uma análise dos procedimentos reais dos festivais.

A maioria dos festivais acompanhados da prática dessa troca de ofensas verbais é encontrada nos registros folclóricos da modernidade, sendo que, infelizmente, há poucos registros da época pré-moderna.

No livro Hinami kiji (Artigo Diário), do Período Edo (1603-1867), há uma descrição da famosa cerimônia religiosa de passagem de ano realizada no Santuário Gion:

"No Santuário Gion, altas horas da noite do último dia do ano, apaga-se toda a iluminação, com exceção das velas que iluminam o altar, e, no escuro, os participantes deliberadamente trocam insultos. Mesmo reconhecendo o autor dos insultos pela voz, não se pode brigar nem guardar rancor."

Uma descrição mais detalhada do mesmo festival pode ser encontrada não em um registro, mas na ficção Seken munesan yô (Acertos de contas sentimental perante a sociedade) de Ihara Saikaku. Segundo este, na Antigüidade, os participantes posicionavamse em duas filas paralelas e, como se fosse um torneio, ordenadamente trocavam insultos 
numa espécie de desafio. Porém, os insultos trocados eram do tipo aparentemente ingênuos por serem entre desconhecidos, sem a personalização ou a aspereza próprias de conhecidos, tais como "você irá parar no túmulo engasgando-se com mochi (bolinho de massa de arroz) no terceiro dia do ano" ou "sua esposa ficará louca no primeiro dia do ano e jogará seu filho no poço"

A localização privilegiada do Santuário Gion no centro da capital Quioto e também a grandeza dos festivais ali realizados contribuem para que os participantes sejam desconhecidos. Neste ponto, é totalmente diferente dos festivais que possuem como cenário, as pequenas comunidades de santuários xintoístas da maioria das aldeias. $\mathrm{O}$ caráter genérico dos insultos demonstra este fato.

Diferentemente dos festivais que culminavam em troca de insultos comuns, havia práticas que visavam a revelar condutas imorais concretas, como o Zattona (Falando por alto) da região de Shiogama, Província de Miyagi e o Chiba warai (Riso de Chiba) do Templo Chiba, situado na província de mesmo nome.

Zattona é realizado na noite de 15 de janeiro, nos bairros próximos ao Templo Shiogama. Em cada bairro, as crianças escolhem, sem discriminar sexo ou idade, uma pessoa que tem, no cotidiano, comportamento condenável e, reunindo-se na entrada dos fundos da casa do escolhido, relatam em voz alta e em coro as referidas práticas e depois desaparecerem na noite. Assim, uma vez que um segredo tornase público a partir dessa noite, denegrindo sua reputação, conta-se que as pessoas passam a ter cautela em seus atos. A denominação Zattona, literalmente "de um modo geral", "grosso modo, resumindo", originou-se do fato de que, no início da revelação, uma criança usa o refrão "zattona, zattona, koko ni hanashi ari to na" ("Falando bem por cima, bem por alto, dizem que aqui há uma história para contar") e as outras crianças perguntam "qual então?" antes de relatar o fato propriamente dito.

No caso do Chiba warai, os moradores das redondezas do Templo Chiba reúnemse na noite do último dia do ano e, cobrindo o rosto com um pano e também a cabeça para não serem identificados pelo corte de cabelo, relatam as parcialidades, as boas e más atitudes dos ocupantes de cargos públicos da aldeia, tais como o chefe e os anciãos, intercalando gargalhadas. Assim, aqueles que têm comportamento condenável, tal como o de ser ingrato com os pais, também viram motivo de chacota. Desse modo, tanto o primeiro como o segundo passam a ter cautela em suas atitudes, evitando serem alvo de zombaria.

Considerando-se tais registros, pode-se afirmar que os eventos acima descritos possuem certamente uma função de sanção social.

Torna-se necessário, assim, esclarecer em quais condições esse tipo de função social torna-se possível.

Um protótipo de práticas semelhantes ao festival de insulto nas sociedades tribais pode ser o chamado "song duel" realizado na sociedade esquimó. Este duelo consiste em resolver os conflitos por meio de canções, danças e gestos, ao invés do emprego de armas e da violência, e constitui um exemplo emblemático do mecanismo da sanção social das sociedades tribais. É necessário considerar que a sociedade esquimó não é homogênea, apresenta variação regional, de modo que há significativas 
diferenças nos detalhes descritos por estudiosos, mas segundo a síntese apresentada por E. A Hoebel ${ }^{7}$ pode-se afirmar que segue o seguinte padrão organizacional.

O duelo musical é realizado no verão, época em que os esquimós passam a viver em comunidade, com todos os membros no pátio da aldeia. O estilo da música é padronizado, mas a letra, muitas vezes improvisada, é composta com o intuito de ridicularizar ou ferir o adversário, podendo ser por meio de imitações ou mímicas, e contar, ainda, com o coro dos familiares. Aquele que conseguir mais aplausos e gritos de aprovação do público será consagrado vencedor. Entretanto, a recompensa é apenas o conforto espiritual, no sentido de resgate da dignidade pessoal, não cabendo recompensas materiais e afins.

As questões resolvidas por meio do duelo musical incluem todos os tipos de conflitos e ressentimentos, excluindo-se, normalmente, os casos de homicídio. A região leste da Groenlândia parece ser exceção.

Por piores que sejam os insultos, é proibido aos concorrentes expressarem raiva ou fúria. Como já foi dito, a regra é ser aclamado pelos presentes ou vencer o oponente fazendo-o se calar, devendo os envolvidos, no final da disputa e da aclamação do vencedor, fazer a reconciliação, exigindo-se, às vezes, uma troca de presentes.

Analisando a causa da eficácia do duelo musical na resolução de conflitos da sociedade esquimó, é necessário apontar, em primeiro lugar, o fato de que predomina, nessa sociedade, o valor social de se evitar a desonra. Ou seja, o temor de que as condutas e fracassos sejam levados ao conhecimento público age como um forte fator inibidor, pois, uma vez cometido o delito, o infrator é punido ao ser obrigado a passar por uma situação vexatória de ser penalizado num duelo musical. Assim, evitar a desonra que permeia a sociedade como um todo constitui um fator indispensável para a eficácia de uma sanção que não é nem material nem física.

Nós, homens modernos, não entendemos tal mentalidade e tendemos a subestimar a força dos valores sociais, como aqueles descritos acima, mas Rattray ${ }^{8}$, por exemplo, citando a tribo africana Ashanti, enfatiza o poder da "ridicularização" como a mais eficaz sanção social para que as normas tradicionais da comunidade sejam respeitadas, chegando a afirmar que talvez ela seja mais temida do que qualquer castigo severo imposto pelo homem, por privar o indivíduo da auto-estima e do respeito dos companheiros. Rattray justifica essa tese lembrando que, pela característica do ambiente onde os Ashanti vivem, um membro ridicularizado pelos companheiros não possui nenhum lugar para se isolar. Porém, em maior ou menor grau, esta realidade é comum para todas as comunidades pré-modernas, inclusive para a dos esquimós.

Ainda, em vários países do Mediterrâneo, especificamente na região meridional da Espanha, existiu na antigüidade uma prática conhecida como vito. Trata-se de um meio de expressar a censura dos habitantes àquele que transgrediu as normas da comunidade. À noite, um grupo de moradores dirige-se à casa do infrator e, em alvoroço, insultam-no por meio de canções. Essas e outras práticas são repetidas até que o infrator

7. Autor de Antropologia Cultural e Social, trad. de Euclides Carneiro da Silva, São Paulo, Cultrix, 1981.

8. R. S. Rattray, Ashanti Law and Constitution (1927). 
resolva abandonar a comunidade. O temor de ser zombado e ridicularizado em público constitui uma poderosa sanção social, especialmente nas culturas mediterrâneas, em que a honra e a vergonha são consideradas valores importantes.

Entretanto, por mais que se considere o peso da desonra, a sanção social parece requerer outras condições para que funcione como um meio eficaz para a solução dos conflitos, impedindo o uso da violência, como o que se dava entre os samurais.

Nesse sentido, é necessário apontar para o fato de inexistir, quase que por completo, o poder judicial ou mesmo a organização policial na sociedade esquimó. Por este motivo, os esquimós tiveram que depender do duelo musical como meio autônomo de resolução de conflitos, mantendo o consenso social de que o resultado do duelo seria, em última instância, a solução definitiva.

Esse caráter de consenso social aparece com nitidez nas regras do duelo musical: não se pode expressar a raiva ou a fúria, por mais que o insulto seja grave; vence aquele que conseguir mais aplausos e aclamação do público; terminada a disputa, as partes são obrigadas a fazer as pazes e, dependendo do caso, trocar presentes para simbolizar a reconciliação. Sem essas regras, certamente o duelo musical abriria caminho para uma disputa corporal.

Como foi anteriormente referido, o "festival de insulto" também possui uma função de sanção social e, nesse sentido, não há dúvidas de que isso se deve à existência de um valor social no Japão que rejeita fortemente a vergonha. Entretanto, é necessário enfatizar que, ao contrário da sociedade esquimó onde o formato do duelo prioriza o embate indivíduo versus indivíduo, como que numa relação entre o acusador e o acusado num tribunal, no Japão, o festival de insulto possui o caráter de punição coletiva de um indivíduo que transgrediu normas específicas da própria coletividade. Além disso, as questões eram de natureza moral e não de incidentes semelhantes aos dos esquimós. A diferença com a sociedade esquimó talvez resida no fato de o Japão ter conseguido, numa fase relativamente inicial de sua história, elaborar um aparato jurídico para as punições.

De qualquer maneira, se o festival de insulto possuía alguma função de sanção social, deveria ter existido algum tipo de regra para garantir o seu funcionamento. De fato, em muitos casos, podem-se encontrar alguns regulamentos que sugerem ser resíduos de regras dessa natureza. Nos documentos folclóricos da modernidade, encontram-se as seguintes regras:

- não brigar, por mais que o insulto seja grave (Festival Matarajin do Templo Môetsu e Festival de Suwa, Nagasaki);

- não apelar para a violência (Festival de Insulto Iwama);

- é estritamente proibido usar a violência (Festival de Briga do Templo Kiyomizu)

- não apelar jamais para a violência. (Festival de Briga do Santuário Toyokawa Inari);

- quem se cala ou briga ao ser derrotado terá problemas com o crescimento do bichoda-seda (Santuário Hinoki Sawadake)

Nota-se que todas as regras são relativas à prática da violência física visando a impedir que o conflito se agrave, e é possível presumir que quase todo festival de insulto tenha regras dessa natureza com as devidas variações. Existiam, ainda, casos 
como os da "Feira de Insultos" do Templo Saishôji que proibia o uso de termos como "ladrão" e "adúltero". Infelizmente, só algumas realizações do festival de insulto podem ser confirmadas no período pré-moderno. Mas, considerando-se, por exemplo, o relato do livro Hinami Kiji, onde consta que a ordem era "não brigar, não guardar rancor" mesmo quando a pessoa é identificada pela voz, pode-se afirmar que tais regras, que impediam que os insultos se desenvolvessem para o uso da agressão física, já existiam desde a antigüidade.

Talvez a garantia do anonimato tenha alguma relação com as regras acima descritas. A prática de se apagar a luz durante o ato, verificada no Santuário Gion, ou ainda na Feira de Insultos do Templo Saishôji, no Festival de Insultos Iwama, no Festival de Risos de Chiba e tantos outros, parece corroborar tal hipótese. A proibição de se fazer qualquer retaliação, mesmo reconhecendo a pessoa, parece ter o efeito de se limitar a ofensa verbal ao âmbito incomum e momentâneo de uma festividade.

Percebe-se, assim, que tais regras são necessárias para que as ofensas verbais não comprometam o relacionamento cotidiano dos membros de uma vila ou aldeia, em um contexto em que todos se conhecem e é difícil manter as condutas individuais em segredo. Especialmente nos casos em que o insulto verbal configura crítica a uma pessoa específica, a obediência às regras acima mencionadas torna-se imprescindível para evitar possíveis desdobramentos mais sérios, como brigas.

\section{O Aparecimento do Poder Judiciário e os Festivais de Ofensa Verbal}

Como vimos analisando com os exemplos dos esquimós e de outros grupos sociais, se a troca de ofensas verbais é algo capaz de funcionar como um meio de sanção social autônoma, e se, por meio da análise dos festivais de ofensa verbal, presumirmos que elas desempenham função semelhante na sociedade japonesa, qual seria a razão para que, após o advento do xogunato, a proibição das ofensas verbais tenha sido promulgada com a justificativa de que viria a ser a causa para discussões e brigas?

A discussão verbal ligar-se ou não aos confrontos violentos são como faces de uma mesma moeda. Somente quando existe uma anuência social de que as palavras são uma forma de solução constante e não casual dos conflitos e quando há determinadas regras para que ela não se desenvolva em agressão física, a discussão verbal pode cumprir a função que dela se espera. O modelo representativo da sociedade que possui essa anuência é a dos esquimós, mas se, com o aparecimento de outros métodos, essas regras de consentimento se afrouxarem, tais discussões serão meras discussões ou bate-bocas que acabam gerando o efeito contrário.

Esses "outros métodos" acima mencionados, significam o aparecimento de uma instância jurídico-policial, aparecimento este que se dá com apoio num poder judicial de maior ou menor grau. Um exemplo concreto disso é apresentado pelo historiador jurídico Nakada Kaoru (1877-1967) em Eiyono Shichiire ("Penhorando a honra").

Segundo o autor, na Alemanha, desde o século XIV, havia uma prática bastante comum relacionada à inadimplência do devedor, chamada "termo de insulto", segundo a qual permitia-se ao credor ridicularizar e ofender o devedor de forma verbal, textual 
ou ainda, por meio de poemas ou pinturas. Só que isso gerou conflitos e discórdias ainda mais acirradas entre as partes envolvidas e, como isso conturbava a paz, a ordem policial imperial de 1577 proibiu tal medida com a seguinte justificativa: "É costume o credor ofender publicamente, por meio de pinturas ou textos desonrosos, um devedor ou o seu fiador quando o primeiro não cumpre suas obrigações, não pagando a dívida cobrada. No entanto, esse ato é por demais ultrajante, podendo gerar muitas brigas e rancores, por isso, é inadmissível em regiões onde existem lei e eqüidade" A frase "em regiões onde existem lei e eqüidade" indica como foi o processo de enfraquecimento do "termo de insulto", até perder seu efeito.

Um exemplo que mostra a passagem de uma instância de sanção social como a dos esquimós para uma nova mudança como essa, pode ser vista no relato sobre os concursos de tambores da tribo Tiv da Nigéria. Assim relata P. Bohanan ${ }^{9}$ sobre a solução de discórdia adotada pela tribo Tiv, semelhante ao duelo musical dos esquimós.

Certa vez, quando dois indivíduos entraram em choque em função do dote de casamento, um deles, na mesma noite, começou a espalhar insultos sobre o outro, com tambores e músicas em som bem alto para que fossem ouvidos por toda a vizinhança. $\mathrm{Na}$ noite seguinte, a família desse indivíduo também tomou parte e os insultos foram cantados em coro. O outro, por sua vez, também começou a cantar para enfrentar o primeiro, mas como não tinha habilidade musical, contratou um especialista para criar músicas que criticassem o oponente, sua esposa e familiares. O primeiro acabou esgotando suas idéias e também pediu ajuda a um especialista, e, nesse ínterim, todas as noites, ambos os lados disputavam entre si oferecendo comida e bebida aos vizinhos, para que um maior número possível de pessoas compartilhassem do grupo com músicas e danças que ridicularizassem o oponente.

Como esse confronto durou mais de três semanas, o chefe da região, por fim, intercedeu temendo que isso se desenvolvesse para uma luta armada. O chefe, então, fez com que eles participassem de um concurso de canto e tambor na sua presença para definir o vencedor. Ao fim do concurso, deu-se um empate com um dos envolvidos ficando com a vitória sobre a questão do dote que deu início à desavença, e o outro, com a vitória do concurso musical.

Foi, na realidade, uma solução que o chefe buscou para evitar a intervenção das autoridades coloniais, o que poderia acontecer se a disputa dos tambores avançasse para o uso da força bruta. Além disso, essa disputa dos tambores não serviu em nada para a solução da desavença inicial em si que era a questão do dote. A decisão do chefe foi a de dividir a vitória entre as partes com um vencedor da contenda e outro vencedor do concurso de tambor. Nesse caso, o concurso de tambor não pode ser absolutamente considerado um meio de solução de conflitos.

Entretanto, o método de pressionar o oponente ganhando um maior número de simpatizantes entre a vizinhança, oferecendo até bebida e comida para divulgar ao máximo a música que injuria o seu oponente, não é diferente do concurso de música dos esquimós. Uma vez que no Congo e outras regiões da África Ocidental é realizado

9. P. Bohanan: autor de Justice and Judgment among the Tiv (1957). 
um tipo de julgamento que dá a vitória ao melhor cantor, presume-se que o sentido pode ser o mesmo no caso da tribo Tiv.

O exemplo dos Tiv é, originariamente, um método de solução de conflito auto= determinado por uma comunidade regional, e podemos dizer que o concurso de tambor realizado sob algumas regras foi perdendo essa função mas, ao mesmo tempo, por terem se afastado do cerceamento das regras, passaram, ao contrário, a desempenhar a função de aumentar a desavença. Essa transformação pode ser atribuída à própria colonização. Ou seja, podemos entender que, com a colonização, surge um poder superior ao da comunidade que reduz a necessidade de se apoiar à antiga forma de solução dos conflitos, função essa que passa a ser exercida pelos órgãos policiais e judiciários das autoridades coloniais.

Desse modo, se entendermos que o exemplo da tribo Tiv, onde a ofensa verbal não funciona como meio de solução dos conflitos, mostra que o método comunitário e local de solução das desavenças foi substituído por um novo e superior órgão policial e judiciário, podemos dizer que isso também se aplica ao que aconteceu ao processo de formação do Goseibai Shikimoku e a sua proibição em relação à ofensa verbal.

Nos tribunais do xogunato Kamakura, acabou por se perder a função que a palavra desempenhava nas reuniões como a dos festivais de insultos enquanto método de solução dos conflitos realizado sob determinadas regras. Por ocasião da solução dos conflitos consuetudinários da comunidade, nem sempre surgiam defesas racionais; às vezes, misturavam-se expressões de ofensa bastante exacerbadas e, seja como for, aquilo que deveria forçar o oponente a se render pelas palavras, oral ou textualmente, foi eliminado como algo prejudicial para as disputas judiciais. Esse é o motivo da proibição das ofensas verbais pelo Goseibai Shikimoku e justamente por isso, as ofensas verbais no tribunal foram particularmente problematizadas.

\section{As Ofensas Verbais e os Ritos de Fertilidade}

A função dos festivais de insultos não era apenas a de ser uma instância de sanção social. Nos documentos legais do xogunato, embora em número bastante reduzido, havia algumas expressões consideradas ofensivas apesar de desprovidas de algum sentido particular subentendido, tais como bokai ni oyobu ou bokai ni kakete (atingir o reino materno). Essas expressões, da mesma forma que oyamaki ou hahamaki (envolvimento maternal) constantes na obra Kokon Chomonj $\hat{u}^{10}$, significam incesto entre mãe e filho.

Mesmo entre as injúrias trocadas nos festivais de insultos, havia expressões próprias como, por exemplo, "Oniga deta, tsubio shiyo" ("O ogro apareceu; vamos fazer sexo") usadas nas Festas das Flores. No festival do Santuário Horohasan, trocavamse palavras vergonhosas que pais e filhos não seriam normalmente capazes de ouvir lado a lado e, nos desfiles dos festivais de lamparinas do Santuário Kamikura de Kumano, insultavam-se as mulheres encontradas no percurso.

10. Kokon Chomonjû: (1254). Coletânea das Narrativas Setsuwa. 
A existência de insultos verbais relacionados ao sexo mostra que o festival de ofensas verbais era uma espécie de rito de fertilidade, ligado à idéia de procriação.

Esses exemplos de injúrias são particularmente difíceis de serem registrados mas, com certeza, essas trocas de insultos com conotação sexual eram bem mais freqüentes do que aparecem nos registros. Nas regiões do Pacífico, a começar da China, não eram raros os insultos com conotação sexual envolvendo a mãe e, embora existissem expressões como essas no Japão, elas desapareceram por completo das expressões modernas. Acredita-se que isso tenha ocorrido porque desde o Período Meiji (18681912) o sexo foi reprimido em nome da moral e, mesmo nos festivais, as partes indecorosas foram eliminadas por completo, ou ao menos superficialmente.

Os aspectos da sanção social e do rito da fertilidade, aqui abordados, não eram coisas excludentes e sim, uma coisa só. Na sociedade pré-moderna, a ordem da sociedade humana ou da comunidade estava intimamente relacionada à fartura ou à escassez dos produtos agrícolas e da caça. Calamidades naturais como a má colheita e a fome não eram fenômenos naturais que seguiam uma relação própria de causa e efeito, dissociados da sociedade humana; pensava-se sim, que eram provenientes de algum distúrbio da "ordem" do universo como um todo, que se ligava tanto à forma de ser da sociedade humana, quanto do ambiente natural que a envolvia. Por conseguinte, os atos que conturbam a ordem da comunidade humana eram condenados como causadores de uma grande influência na ordem geral e, por extensão, como geradores de calamidades como a má colheita.

Por isso, nas festividades, que eram um local dos ritos pela fertilidade, praticavase concomitantemente a troca de injúrias sexuais que se ligavam à reprodução, de um lado, e de outro, a abolição de atos que corroíam ou perturbavam a ordem. Nos festivais de insulto verbal, havia, ainda, a função de se fortalecer a ordem, ou seja, a função de se criar um local de caos momentâneo e incomum.

Segundo M. Wilson" ${ }^{11}$ as pessoas do povo nyakyusa da África pensavam que a origem de todos os infortúnios estava na insatisfação e na ira dos seres humanos, e que, para restabelecer a felicidade, era preciso a pessoa insatisfeita e irada confessar o fato e conceder o perdão. Por exemplo, no caso de uma família que tivesse a infelicidade de ter alguém doente, era preciso descobrir a ira de quem causara a doença e, além de pedir a ela que o confessasse, exigia-se que ela desejasse o seu restabelecimento.

Wilson chama esse ato de confissão seguido de reconciliação e perdão de speak out e a oportunidade de fazê-lo é dado num ritual público. Por exemplo, quando parentes se reúnem por ocasião de matrimônios e funerais, todos explanarão as reclamações e insatisfações que guardam no íntimo. Nessas ocasiões, os participantes exageram propositadamente na bebida para que exponham, "desabafem" o que levam no coração, e a função dos oficiantes ou sacerdotes que realizam tais cerimônias é a de trazer livremente à tona os pensamentos dos participantes de modo a não ficarem ressentimentos. Reclamações e insatisfações como a discórdia entre nora e sogra, insatisfações dos irmãos mais novos em relação aos mais velhos e aos chefes de família, a ira dos mais

11. M. Wilson, Good Company: A Study of Nyakyusa Agevillages (1951). 
idosos para com a irreverência dos jovens, tudo é expresso em forma de brigas, até que, por fim, depois de se falar tudo o que se tinha a dizer, vem o momento da reconciliação, e a cerimônia termina.

O sentido de bureikô (festa desprovida de cerimônia) na sociedade japonesa também se assemelha ao speak out do povo nyakyusa. A bureikô é o local do caos, distanciado momentaneamente da ordem cotidiana, e, as reclamações, as insatisfações e os rancores de ordem corriqueira, aí manifestados, servem, em termos de resultado, como reafirmação e fortalecimento da ordem social. Os eventos chamados de festivais de insultos como a akkô matsuri e akutai matsuri exercem o papel de sanção social e, ao mesmo tempo, uma função social que se liga a essa festa sem cerimônias, que é a bureikô.

A partir do momento em que, pelo estabelecimento da lei, passa a existir uma pressão concreta sobre a ofensa verbal, enquanto sanção social, essa pressão não se restringe simplesmente ao aspecto sancional das festividades de insultos, mas acaba adquirindo a possibilidade de se ligar à repressão das festividades de ofensa verbal como um todo, que inclui também o rito de fertilidade presente na sociedade local. Ao mesmo tempo em que se reprime o insulto sexual, elimina-se também o caos incomum, que não faz parte do cotidiano.

(Tradução de Neide H. Nagae e Wataru Kikuchi) 